\title{
Evidence That Isoniazid and Ethanol Induce the Same Microsomal Cytochrome $P-450$ in Rat Liver, an Isozyme Homologous to Rabbit Liver Cytochrome $P$-450 Isozyme 3a
}

\author{
DENE E. RYAN, DENNIS R. KOOP, ${ }^{*, 1}$ PAUL E. THOMAS, \\ MINOR J. COON, ${ }^{*, 1}$ AND WAYNE LEVIN ${ }^{2}$
}

\begin{abstract}
Laboratory of Experimental Carcinogenesis and Metabolism, Roche Institute of Molecular Biologu, Nutley, New Jersey 07110, and *Department of Biological Chemistry, Medical School, The University of Michigan, Ann Arbor, Michigan 48109
\end{abstract}

Received November 19, 1985, and in revised form January 3, 1986

Cytochrome $P-450$ j has been purified to electrophoretic homogeneity from hepatic microsomes of adult male rats administered ethanol and compared to the corresponding enzyme from isoniazid-treated rats. The enzymes isolated from ethanol- and isoniazidtreated rats have identical chromatographic properties, minimum molecular weights, spectral properties, peptide maps, $\mathrm{NH}_{2}$-terminal sequences, immunochemical reactivities, and substrate selectivities. Both preparations of cytochrome $P-450 \mathrm{j}$ have high catalytic activity in aniline hydroxylation, butanol oxidation, and $N$-nitrosodimethylamine demethylation with turnover numbers of 17-18,37-46, and $15 \mathrm{nmol}$ product/min/ $\mathrm{nmol}$ of $P-450$, respectively. A single immunoprecipitin band exhibiting complete identity was observed when the two preparations were tested by double diffusion analysis with antibody to isoniazid-inducible cytochrome $P-450 \mathrm{j}$. Ethanol- and isoniazid-inducible rat liver cytochrome $P-450 \mathrm{j}$ preparations have also been compared and contrasted with cytochrome $P-450$ isozyme 3 a, the major ethanol-inducible isozyme from rabbit liver. The rat and rabbit liver enzymes have slightly different minimum molecular weights and somewhat different peptide maps but similar spectral, catalytic, and immunological properties, as well as significant homology in their $\mathrm{NH}_{2}$-terminal sequences. Antibody to either the rat or rabbit isozyme cross-reacts with the heterologous enzyme, showing a strong reaction of partial identity. Antibody against isozyme $3 a$ specifically recognizes cytochrome $P-450 \mathrm{j}$ in immunoblots of induced rat liver microsomes. Aniline hydroxylation catalyzed by the reconstituted system containing cytochrome $P-450 \mathrm{j}$ is markedly inhibited ( $>90 \%$ ) by antibody to the rabbit protein. Furthermore, greater than $85 \%$ of butanol or aniline metabolism catalyzed by hepatic microsomes from ethanol- or isoniazid-treated rats is inhibited by antibody against isozyme 3a. Results of antibody inhibition studies suggest that cytochrome $P-450 \mathrm{j}$ is induced four-to sixfold by ethanol or isoniazid treatment of rats. All of the evidence presented in this study indicates that the identical cytochrome $P-450, P-450 \mathrm{j}$, is induced in rat liver by either isoniazid or ethanol, and that this isozyme is closely related to rabbit cytochrome $P-450$ isozyme $3 a$. (C) 1986 Academic Press, Inc.

Cytochrome $P-450$, the terminal electron acceptor and substrate-binding site of the

\footnotetext{
1 This work was supported in part by Grants AA06756 (to D.R.K.) and AA-06221 (to M.J.C.) from the National Institute on Alcohol Abuse and Alcoholism.

2 To whom correspondence should be addressed.
}

hepatic microsomal mixed-function oxidase system, catalyzes the metabolism of an almost limitless number of xenobiotics as well as certain endogenous compounds (1-3). This enzyme system serves as a route of detoxification and, in contrast, also as a route of metabolic activation to yield re- 
active metabolites that initiate toxic and carcinogenic events (4). Hepatic microsomes contain multiple cytochrome $P-450$ isozymes, each possessing broad and overlapping substrate selectivity, that contribute to the metabolic versatility of this system. The cytochrome $P-450$ population present in microsomes is subject to complex regulation, being dependent on age and sex as well as treatment of an animal with inducers.

Two clinically relevant hepatotoxins, isoniazid and ethanol, have been shown to be inducers of rat hepatic microsomal cytochrome $P-450$ with inducing properties unlike phenobarbital or $\beta$-naphthoflavone (3-methylcholanthrene) (5-15) but similar to each other. Although neither compound is a potent inducer of total microsomal cytochrome $P-450$, treatment of rats with either isoniazid or ethanol results in a shift in the microsomal CO-reduced difference spectral maximum from 450 to $451-452 \mathrm{~nm}$ $(7,9,10,15)$. Microsomal electrophoretic patterns indicate that treatment of rats with either of these inducers results in the appearance of a protein-staining band of the same mobility $\left(M_{\mathrm{r}} \sim 51,000\right)(7,8,11$, 14, 15). Enhanced rat liver microsomal metabolism of certain substrates, most notably aniline $(6,9,10,15)$ and ether anesthetics $(9,12)$, is also associated with both isoniazid and ethanol induction. Ethanol treatment of rats has also been characterized by increased rates of metabolism of alcohols (7) and $\mathrm{NDMA}^{3}$ (11) in rat liver, but these pathways have not been studied in rats administered isoniazid. Koop et al. $(16,17)$ purified cytochrome $P-450$ isozyme $3 a$ originally from liver microsomes of ethanol-treated (16) and subsequently from imidazole-treated rabbits (17). This enzyme, which exhibits high catalytic activity toward alcohol and aniline metabolism (16, $18,19)$, as well as NDMA demethylation (20), has been shown to be inducible in rabbit liver by ethanol and isoniazid as well as other agents including trichloroethyl-

\footnotetext{
${ }^{3}$ Abbreviations used: androstane disulfate, $5 \alpha$-androstane-3 $\alpha, 17 \beta$-diol-3,17-disulfate; NDMA, $N$-nitrosodimethylamine; SDS, sodium dodecyl sulfate; TCA, trichloroacetic acid; IgG, immunoglobulin G.
}

ene, acetone, and pyrazole (21). The results of Ingelman-Sundberg and Jornvall (22) suggest that benzene induces the same cytochrome $P-450$ as ethanol in rabbit liver.

Cytochrome $P-450 \mathrm{j}$, which has recently been purified to electrophoretic homogeneity from isoniazid-treated adult male rats, appears to be a major protein induced in hepatic microsomes after administration of this drug (15). This cytochrome is distinct from nine other purified rat hepatic microsomal cytochromes $P-450$ ( $P$ $450 \mathrm{a}-P-450 \mathrm{i})(14,15,23)$ but has several properties similar to rabbit liver isozyme $3 a$. Both cytochrome $P-450 \mathrm{j}$ and rabbit liver isozyme $3 a$ have similar spectral and catalytic properties, and 13 of the first 19 amino acid residues of the two proteins are identical $(15,16)$. In the present paper, we report the characterization of cytochrome $P-450$ j from ethanol-treated adult male rats and present a comparison with the corresponding enzyme from isoniazidtreated rats and with isozyme $3 a$ from ethanol-treated rabbits.

\section{EXPERIMENTAL PROCEDURES}

Purification of microsomal enzymes. Forty adult male Long Evans rats (Blue Spruce Farms, Altamont, N. Y.) at 8 weeks of age were administered isoniazid (Aldrich) in drinking water $(0.1 \%, w / v)$ for 10 days as previously described (15). In other experiments, animals were maintained on a liquid diet containing ethanol for approximately 5 weeks by the protocol reported by Lieber and De Carli (24). Hepatic microsomes were prepared from both groups of rats, and the specific contents ranged from 1.0 to $1.5 \mathrm{nmol}$ of cytochrome $P-450 / \mathrm{mg}$ of protein.

Cytochrome $P-450$ j was purified to electrophoretic homogeneity from hepatic microsomal preparations of isoniazid- or ethanol-treated rats by the method recently reported (15). In hoth cases, the purified enzymes had a specific content of 11-13 nmol of cytochrome $P-450 / \mathrm{mg}$ protein, and the overall recovery of purified cytochrome $P-450 \mathrm{j}$ from total microsomal cytochrome $P-450$ was $1-2 \%$. Cytochrome $P-450$ isozyme $3 \mathrm{a}$ was isolated from hepatic microsomes of ethanol-treated adult New Zealand male rabbits by the procedure of Koop et al. (16).

NADPH-cytochrome $P-450$ reductase was purified from phenobarbital-treated rats to a specific activity of $35,000-40,000$ units $/ \mathrm{mg}$ protein by a combination of the methods of Dignam and Strobel (25) and Yasukochi and Masters (26). Enzyme activity was determined by the procedure of Phillips and Langdon 
(27), and one unit of reductase is defined as that amount catalyzing the reduction of $1 \mathrm{nmol}$ of cytochrome $\mathrm{c} / \mathrm{min}$ at $22^{\circ} \mathrm{C}$. Electrophoretically homogeneous reductase from phenobarbital-treated rabbits, purified as described (28), was used in certain experiments as indicated.

Preparation of antibodies. Antibodies to cytochrome $P$-450 isozyme 3 a were elicited in female sheep as previously described (29). Antisera or purified IgG was used as designated. Antibodies to rat hepatic cytochrome $P-450$ j were produced in New Zealand rabbits by the protocol of Thomas et al. (30). Ouchterlony double diffusion plates were prepared with or without the addition of detergent as described (30).

Assays for catalytic activity. The following references contain the methods for assays of the various substrates: $\left[N-m e t h y l-{ }^{14} \mathrm{C}\right]$ benzphetamine (31), [2$\left.{ }^{14} \mathrm{C}\right]$ hexobarbital $(32,33)$, benzoa[a]pyrene (34), [4,6${ }^{3} \mathrm{H}$ ]zoxazolamine (35), [2- $\left.{ }^{8} \mathrm{H}\right]$ estradiol-17 $\beta \quad(36)$, 7ethoxycoumarin (37), $p$-nitroanisole (38), androstane disulfate $(39,40)$, aniline $(16,41)$, NDMA $(42,43)$, and butanol $(18,44)$. Metabolites of testosterone were analyzed as previously reported $(45,46)$.

Catalytic activity was assayed under conditions in which product formation was proportional to hemoprotein concentration and time of incubation. In reconstitution experiments, other purified cytochrome $\boldsymbol{P}$-450 isozymes with known activity were included for reference. Saturating amounts of NADPH-cytochrome $P-450$ reductase and optimal dilauroylglyceryl-3-phosphorylcholine (15-30 $\mu \mathrm{M}$, depending on the substrate utilized) were used in all experiments. The phospholipid (1.5 mM) was prepared in water and sonicated immediately before use.

To determine the effect of anti-3a IgG on aniline hydroxylation catalyzed by the purified cytochromes $P-450$, various ratios of sheep anti-3a IgG to preimmune IgG yielding a total of $1 \mathrm{mg}$ were preincubated for $3 \mathrm{~min}$ at $37^{\circ} \mathrm{C}$ with all of the assay components except NADPH. The reaction was started with $\mathrm{NADPH}$, the samples were incubated for $10 \mathrm{~min}$ at $37^{\circ} \mathrm{C}$, and the reaction was stopped by the addition of TCA. Inhibition of microsomal aniline and butanol metabolism by anti-3a IgG was measured following the same protocol, but the reaction mixtures contained $0.2 \mathrm{mg}$ of microsomal protein, and the sum of sheep anti-3a IgG and preimmune IgG was $2.0 \mathrm{mg}$ of protein.

Electrophoretic methods, peptide maps, and immunoblots. SDS-polyacrylamide gel electrophoresis was performed according to the method of Laemmli (47) in a separating gel containing $7.5 \%$ acrylamide. Protein was detected by silver staining as previously described (48). The procedure for immunoblots of microsomal samples and purified isozymes and detection with anti-3a IgG has been reported earlier by Koop et al. (21).

Limited proteolytic digestion of the purified hemoproteins in the presence of SDS was conducted as described by Cleveland et al. (49). The cytochromes $P-450$ were incubated with either chymotrypsin or Staphylococcus aureus V8 protease for $10 \mathrm{~min}$ at $37^{\circ} \mathrm{C}$ at protein ratios given in the figure legend. The proteolytic digests were subjected to SDS-polyacrylamide gel electrophoresis in separating gels containing $12.5 \%$ acrylamide. In certain experiments, the gels were stained with Coomassie blue $\mathrm{R}-250$ as previously reported (50). In other experiments, immunoblots of the proteolytic digests were probed with anti-3a antiserum (1:2500 dilution) to detect immunoreactive peptides by a protocol previously described (51).

Other methods. Protein was determined by the method of Lowry et al. (52) with crystalline bovine serum albumin as the standard. Cytochrome $P-450$ content was calculated from the $\mathrm{CO}$-reduced difference spectrum on the basis of an extinction coefficient of $91 \mathrm{mM}^{-1} \mathrm{~cm}^{-1}$ according to the method of Omura and Sato (53). The binding of ethylisocyanide ( $2.0 \mathrm{~mm}$ final concentration) to ferrous cytochrome $P-450$ was measured as previously reported (54).

\section{RESULTS AND DISCUSSION}

\section{Isozyme Characterization}

Hepatic microsomes, isolated from adult male rats that had been maintained on a liquid diet containing ethanol according to the regimen of Lieber and De Carli (24), were subjected to the procedure recently developed for the purification of cytochrome $P-450$ j from isoniazid-treated rats (15). At each step in the purification, the preparation from ethanol-treated rats behaved identically to the corresponding fraction from isoniazid-treated animals. Electrophoretically homogeneous cytochrome $P-450 \mathrm{j}$ was thus isolated from ethanol-treated rats, with a 1-2\% recovery of total microsomal cytochrome $P-450$. As shown in Fig. 1, the enzyme purified from ethanol-treated animals was identical in mobility (minimum $M_{\mathrm{r}} 51,500$ ) to cytochrome $P-450 \mathrm{j}$ from isoniazid-treated rats. A protein-staining band with the same migration as cytochrome $P-450 \mathrm{j}$ appeared to be selectively induced in rat hepatic microsomes by ethanol as well as isoniazid. Very little of this peptide was observed in the electrophoretic pattern of microsomes from untreated rats. Rat liver cytochrome $P-450$ j apparently exhibits a different minimum molecular mass in the gel system of Laemmli (47) than does cytochrome $P$ - 


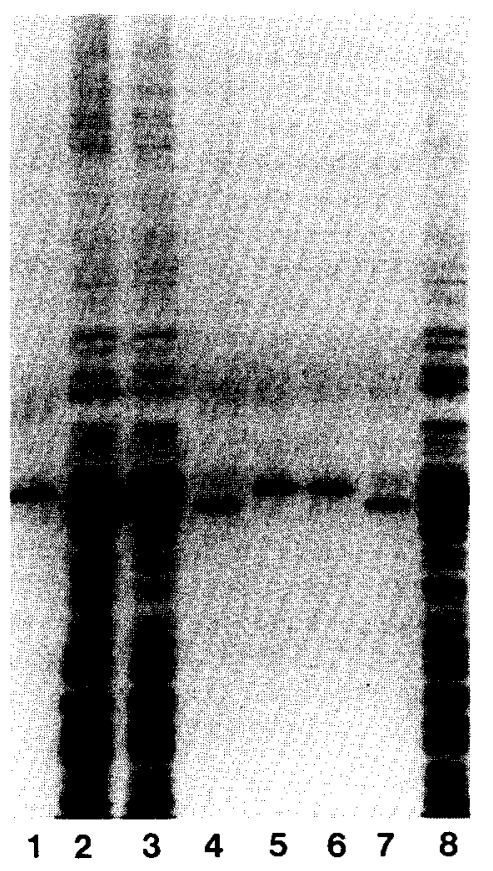

FIG. 1. SDS-gel of hepatic microsomes and purified cytochromes $P-450$. Microsomes from control (well 2 ), isoniazid-treated (well 3 ), and ethanol-treated rats (well 8) were each applied to the gel ( $2 \mu \mathrm{g}$ of protein). Each of the purified enzymes was applied to the gel at the level of $20 \mathrm{ng}$ of protein. Wells 1 and 5 contained cytochrome $P-450$ j from isoniazid-treated rats, wells 4 and 7 contained ethanol-inducible rabbit liver cytochrome $P-450$ isozyme $3 a$, and well 6 contained cytochrome $P-450$ j from ethanol-treated rats.

450 isozyme $3 a$, the major ethanol-inducible rabbit liver isozyme.

Both isoniazid and ethanol treatments of rats have been associated with an upward shift in the microsomal cytochrome $P-450$ CO-reduced difference spectral maximum relative to the peak observed with microsomes from untreated animals $(7,9$, 10, 15). The CO-reduced difference spectra of the cytochrome $P-450$ j preparations from isoniazid- and ethanol-treated rats were recorded and found to be identical, with maxima at $451.5 \mathrm{~nm}$ (data not shown). Neither enzyme preparation had a significant amount of cytochrome $P-420$. The reduced-carbonyl difference spectrum of rabbit cytochrome $P-450$ isozyme $3 \mathrm{a}$ is similar to that of cytochrome $P-450 \mathrm{j}$, having been reported to have a maximum at $452 \mathrm{~nm}$ (16).
The characteristics of the absolute oxidized spectrum of cytochrome $P-450 \mathrm{j}$ from either ethanol- or isoniazid-treated rats are indicative of a high-spin ferric hemoprotein. With both proteins, an absorption maximum at $395 \mathrm{~nm}$ was observed, and the extinction coefficient was calculated to be 90-95 $\mathrm{mM}^{-1} \mathrm{~cm}^{-1}$ (data not shown). As reflected by the spectral properties, the heme chromophore appears to be identical in both preparations of cytochrome $P-450 \mathrm{j}$. The absolute oxidized spectral features of cytochrome $P-450$ j are reminiscent of those described for rabbit liver isozyme 3a (16).

When the ethylisocyanide difference spectrum of ferrous cytochrome $P-450 \mathrm{j}$ from ethanol-treated rats was recorded at $\mathrm{pH} 7.4$, two spectral maxima were generated at 458 and $430 \mathrm{~nm}$ with a peak ratio of 0.62 (data not shown). The characteristics of this spectrum are identical to those observed when this ligand is bound to ferrous cytochrome $P-450$ j from isoniazidtreated rats (15).

The $\mathrm{NH}_{2}$-terminal sequence of cytochrome $P-450$ j from isoniazid-treated rats, determined by Edman degradation for the first 19 residues, was previously identified as Ala-Val-Leu-Gly-Ile-Thr-Ile-AlaLeu-Leu-Val-Trp-Val-Ala-Thr - Leu Leu-Val-Ile (15). The same $\mathrm{NH}_{2}$ terminus has been established for the enzyme from ethanol-treated rats, ${ }^{4}$ which confirms the purity of the preparation and establishes that the cytochromes from both sources are identical in this region of the protein. The sequence showed very little, if any, homology with the $\mathrm{NH}_{2}$-terminal sequences of other rat and rabbit liver cytochromes $P-450$, with the exception of rabbit cytochrome $P-450$ isozyme $3 a$. Thirteen of the first 19 residues of cytochrome $P-450$ j are identical to those of rabbit liver cytochrome $P-450$ isozyme $3 a$, as previously reported $(15,16)$.

A comparison of the catalytic activities of cytochrome $P-450 \mathrm{j}$ from ethanol- and isoniazid-treated rats is given in Table $I$. Both the catalytic effectiveness and substrate selectivities of the two isozyme

\footnotetext{
${ }^{4}$ M. Haniu, D. E. Ryan, W. Levin, and J. E. Shively, unpublished observation.
} 
TABLE I

Catalytic Activity of Purified Cytochrome $P-450 j$

\begin{tabular}{|c|c|c|c|c|}
\hline \multirow[b]{2}{*}{ Substrate } & \multirow[b]{2}{*}{$\begin{array}{l}\text { Concentration } \\
\qquad(\mathrm{mM})\end{array}$} & \multirow[b]{2}{*}{ Reaction } & \multicolumn{2}{|c|}{$\begin{array}{c}\text { Activity (nmol product/ } \\
\text { min/nmol cytochrome } \\
P-450 \mathrm{j})\end{array}$} \\
\hline & & & Isoniazid & Ethanol \\
\hline Hexobarbital & 0.7 & 3-Hydroxylation & $<1.0$ & $<1.0$ \\
\hline Benzphetamine & 1 & N-Demethylation & 6.7 & 6.4 \\
\hline 7-Ethoxycoumarin & 0.5 & O-Deethylation & 0.9 & 0.8 \\
\hline Benzo $[a] p y r e n e$ & 0.08 & 3/9-Hydroxylation & $<0.1$ & $<0.1$ \\
\hline Zoxaxolamine & 0.25 & 6-Hydroxylation & 5.3 & 5.5 \\
\hline Estradiol-17 $\beta$ & 0.1 & 2-Hydroxylation & 0.2 & 0.2 \\
\hline$p$-Nitroanisole & 1 & O-Demethylation & 1.9 & 1.9 \\
\hline Testosterone & 0.12 & Hydroxylation & $<0.1$ & $<0.1$ \\
\hline Androstane disulfate & 0.2 & Hydroxylation & $\leqslant 0.1$ & $\leqslant 0.1$ \\
\hline Aniline & 2 & $p$-Hydroxylation & 17.7 & 17.0 \\
\hline NDMA & 5 & N-Demethylation & 15.2 & 15.2 \\
\hline Butanol & 30 & Oxidation & 37.5 & 45.8 \\
\hline
\end{tabular}

Note. The catalytic activity of purified cytochrome $P-450$ j was determined under conditions in which product formation was proportional to time of incubation and isozyme concentration. Saturating NADPH-cytochrome $P-450$ reductase and optimal phosphatidylcholine concentrations were used in all experiments. Butanol oxidation was measured in the presence of reductase from rabbit liver, whereas the metabolism of the other substrates was determined with the purified rat liver reductase.

preparations are indistinguishable for all of the substrates and types of reactions studied. Neither hemoprotein had measurable activity toward hexobarbital, benzo $[a]$ pyrene, testosterone, or androstane disulfate. Although cytochrome $P$ $450 \mathrm{j}$ did catalyze the metabolism of benzphetamine, 7-ethoxycoumarin, zoxazolamine, estradiol-17 $\beta$, and $p$-nitroanisole, the rates were significantly lower than observed with several other rat liver cytochrome $P-450$ isozymes $(14,23)$. In contrast to the results with these substrates, cytochrome $P-450$ j exhibited high catalytic activity in $p$-hydroxylation of aniline, demethylation of NDMA, and oxidation of butanol with turnover numbers of 17-18, 15 , and 38-46 $\mathrm{nmol} \mathrm{product} / \mathrm{min} / \mathrm{nmol} \mathrm{cy}-$ tochrome $P-450$ j, respectively. Several laboratories have reported an association between ethanol induction in rats and increased microsomal metabolism of aniline, NDMA, and alcohols $(6,7,10,11)$, which may be a reflection of increased levels of cytochrome $P-450$ j in these animals.
The catalytic profile of cytochrome $P$ $450 \mathrm{j}$ closely parallels that of rabbit liver ethanol-inducible isozyme 3a. Isozyme 3a has been shown to exhibit low activity toward certain xenobiotics (ethylmorphine, chlorcyclizine, and 7-ethoxycoumarin) but efficiently metabolizes aniline and several alcohols (ethanol, propanol, and butanol), as well as NDMA (16-20). The turnover number for $p$-hydroxylation of aniline by isozyme $3 a$ was reported to be $12.6 \mathrm{nmol} p$ aminophenol $/ \mathrm{min} / \mathrm{nmol}$ cytochrome $P-450$ (18), a value very similar to those obtained for the cytochrome $P-450 \mathrm{j}$ preparations (Table I). The capacity of both cytochrome $P-450 \mathrm{j}$ and cytochrome $P-450$ isozyme $3 \mathrm{a}$ to oxidize butanol is also analogous. Incubations containing isozyme $3 \mathrm{a}$ were included in the assay of butanol oxidation shown in Table I. Under conditions in which butanol metabolism catalyzed by cytochrome $P-450 \mathrm{j}$ proceeded at $38-46$ $\mathrm{nmol} / \mathrm{min} / \mathrm{nmol}$ cytochrome $P-450$, the turnover number for isozyme $3 a$ was 31 . Isozyme $3 \mathrm{a}$ has been reported to catalyze 
the metabolism of NDMA with a $K_{m}$ of 2.9 $\mathrm{mM}$ and a $V_{\max }$ of $9.3 \mathrm{nmol} / \mathrm{min} / \mathrm{nmol} \mathrm{cy}-$ tochrome $P-450$, which was the highest activity among several purified rabbit liver isozymes examined (20). Antibodies to isozyme 3a dramatically inhibited the low $K_{m}$ demethylase activity in microsomes from control- or ethanol-treated rabbits, indicating that cytochrome $P$-450 isozyme $3 a$ is primarily responsible for this activity in microsomes (55).

\section{Immunochemical Reactivities}

Antibodies, because of their specificity, have become increasingly useful probes of the structure and function of different cytochrome $P-450$ isozymes. Thus, antibodies to cytochrome $P-450 \mathrm{j}$, isolated from isoniazid-treated rats, were produced in rabbits by a previously described protocol (30). Ouchterlony double diffusion analysis was used to examine the reactivity of cytochrome $P-450 j^{5}$ from both ethanol- and isoniazid-treated rats, as well as rabbit liver cytochrome $P-450$ isozyme $3 a$ with antibodies prepared against the rat and rabbit isozymes, with the results shown in Fig. 2. As evidenced by the well-defined immunoprecipitin bands formed, antibody to the rat protein recognizes the rabbit hemoprotein, and the rat cytochrome $P-450 \mathrm{j}$ preparations are cross-reactive with antibody to rabbit isozyme $3 \mathrm{a}$ (Fig. 2). A single sharp immunoprecipitin band showing complete identity was formed between the two cytochrome $P-450$ j preparations when tested against antibodies to the rat or rabbit isozyme. These results indicate that the antigenic determinants of cytochrome $P$ $450 \mathrm{j}$, purified from either ethanol- or isoniazid-treated rats, are identical. A reaction of partial identity, as evidenced by spurring of the precipitin bands, was observed when isozyme $3 a$ was tested against these antibodies, suggesting that the rabbit enzyme shares some, but not all, antigenic determinants with rat liver cytochrome $P$ $450 j$. When Ouchterlony plates were pre-

\footnotetext{
${ }^{5}$ As previously reported (15), cytochrome $P-450 \mathrm{j}$ is not recognized by antibodies prepared against cytochromes $P-450 \mathrm{a}-P$-450f.
}

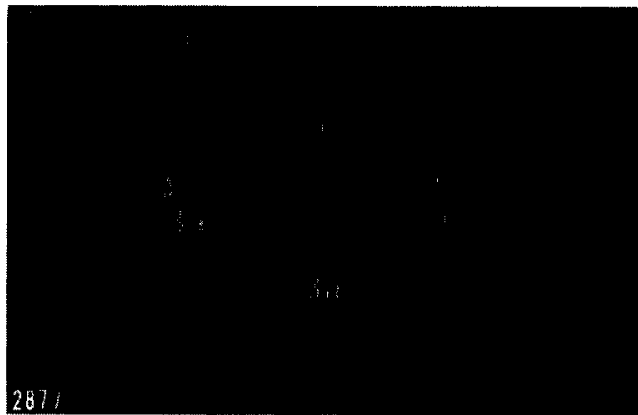

FIG. 2. Ouchterlony double-diffusion analysis of rat liver cytochrome $P-450 \mathrm{j}$ preparations and ethanol-inducible rabbit liver isozyme 3a. Antibodies to cytochrome $P-450 \mathrm{j}$ from isoniazid-treated rats $(30)$ and isozyme $3 a$ (29) were prepared as previously reported. The immunodiffusion plate was composed of components described (30) but no detergent was present in the medium. Antisera were diluted by half with phosphate-buffered saline and added to the wells indicated. Purified cytochrome $P-450 \mathrm{j}$ from isoniazid (IS)- and ethanol (ET)-treated rats and rabbit liver cytochrome $P-450$ isozyme 3 a were added to the wells at $6.8-7.1$ $\mathrm{nmol} / \mathrm{ml}$. The remaining wells contained only phosphate-buffered saline.

pared in the presence of detergent (30), similar results were obtained except that the cross-reactivity of the heterologous protein with each antibody was weaker compared to the reactions in the absence of detergent. Thomas et al. (56) and Ryan et al. (14) have shown previously that the presence of detergent partially inhibits immunoprecipitation between an antibody and a cross-reactive heterologous protein.

Since substantial cross-reactivity was observed by immunodiffusion when antibody to rabbit cytochrome $P-450$ isozyme $3 a$ was tested against purified rat cytochrome $P-450 \mathrm{j}$, this antibody was used to probe immunoblots of rat liver microsomal preparations and purified isozymes. As shown in Fig. 3, cytochrome $P-450 \mathrm{j}$ from either isoniazid- (well 4) or ethanol-treated rats (well 5) was detected by the antibody, as was the antigen, isozyme $3 a$ (wells 1 and 7). A stained protein band of the same mobility as cytochrome $P-450 \mathrm{j}$ (minimum $M_{r}$ $=51,500$ ) was observed with the microsomal preparations from untreated (well 2 ), isoniazid-treated (well 3), and ethanoltreated rats (well 6), suggesting that the 


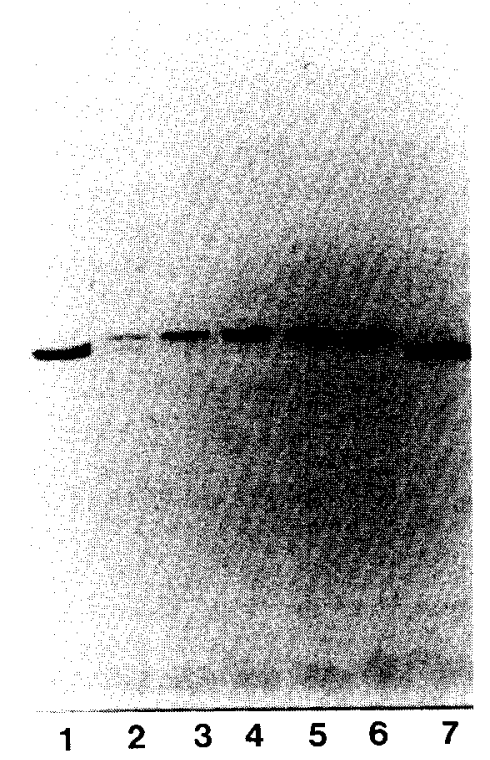

FIG. 3. Immunoblot of rat hepatic microsomes, purified cytochrome $P-450$ j preparations, and isozyme $3 a$. Wells 1 and 7 contained isozyme $3 a$; wells 4 and 5 contained cytochrome $P-450 j$ from isoniazid- and ethanol-treated rats, respectively. The purified proteins were each applied to the gel at the level of 0.1 $\mu \mathrm{g}$ protein. Hepatic microsomes from untreated rats (well 2), isoniazid-treated rats (well 3), and ethanoltreated rats (well 6) were applied at the level of 2.0 $\mu \mathrm{g}$ of protein. Electrophoresis was performed, and the proteins were transferred to nitrocellulose and immunochemically stained with anti-3a IgG.

same protein is induced by both of these treatments. Microsomes from untreated, but not induced, rats appear to contain a second immunoreactive protein, as evidenced by the relatively weak immunochemical recognition of a protein of lower minimum $M_{\mathrm{r}}$ in this sample. Based on the relative staining intensities shown in Fig. 3 , the amount of immunochemically detected cytochrome $P-450$ j is significantly greater in microsomes from isoniazid- or ethanol-treated rats relative to levels in untreated rats. This increase is visually apparent since the same amount of protein from each microsomal preparation was applied to the gel.

Both protein and immunochemical staining were used to examine the limited proteolytic digests of cytochromes $P-450 \mathrm{j}$ from isoniazid- and ethanol-treated rats and rabbit isozyme $3 \mathrm{a}$, with the results shown in Fig. 4 . In part $A$, where the two preparations of cytochrome $P-450 \mathrm{j}$ were incubated with either chymotrypsin or $S$. aureus V8 protease and electrophoresis was carried out in a gel containing $12.5 \%$ acrylamide, identical peptide maps were generated, indicating that these proteins are indistinguishable. On the basis of susceptibility to proteolytic attack by these proteases, cytochrome $P-450$ j from ethanol-treated rats is structurally the same as isoniazid-inducible cytochrome $P-450 \mathrm{j}$. Although this method is not definitive, this approach is sensitive enough to detect the very minor structural differences between rat liver cytochromes $P-450 \mathrm{~b}$ and $P-450 \mathrm{e}$ (23), as well as strain variations in cytochrome $P-450 \mathrm{~b}$ (57). The electrophoretic patterns of proteolytic digests of rabbit liver isozyme $3 \mathrm{a}$, as shown in Fig. 4A, showed some similarities but were clearly distinct from the peptide maps of cytochrome $P-450 \mathrm{j}$ preparations. Therefore, despite the significant immunochemical homology among the rat and rabbit isozymes, structural differences are apparent from these results. Interestingly, however, although several of the peptides of cytochrome $P-450$ j did not align with corresponding peptides of cytochrome $P-450$ isozyme $3 \mathrm{a}$, there was a similarity in overall patterns of digestion between the rat and rabbit enzymes. The major peptides of cytochrome $P-450 \mathrm{j}$ and isozyme $3 \mathrm{a}$, generated by digestion with either protease, appear to have similar but not identical mobility in SDS-polyacrylamide gels. The differences observed in the peptide maps of cytochrome $P-450$ j compared to isozyme $3 \mathrm{a}$ are not surprising since amino acid substitutions are known to occur between homologous isozymes in different species (58).

In Fig. 4B, the proteolytic peptides of cytochrome $P-450 \mathrm{j}$ and isozyme 3 a were immunochemically stained by using antibody to the rabbit protein to determine if all of the peptides of cytochrome $P-450 \mathrm{j}$ were recognized by this antibody. As was observed by staining with Coomassie blue R250 , the proteolytic digests of both prepa- 

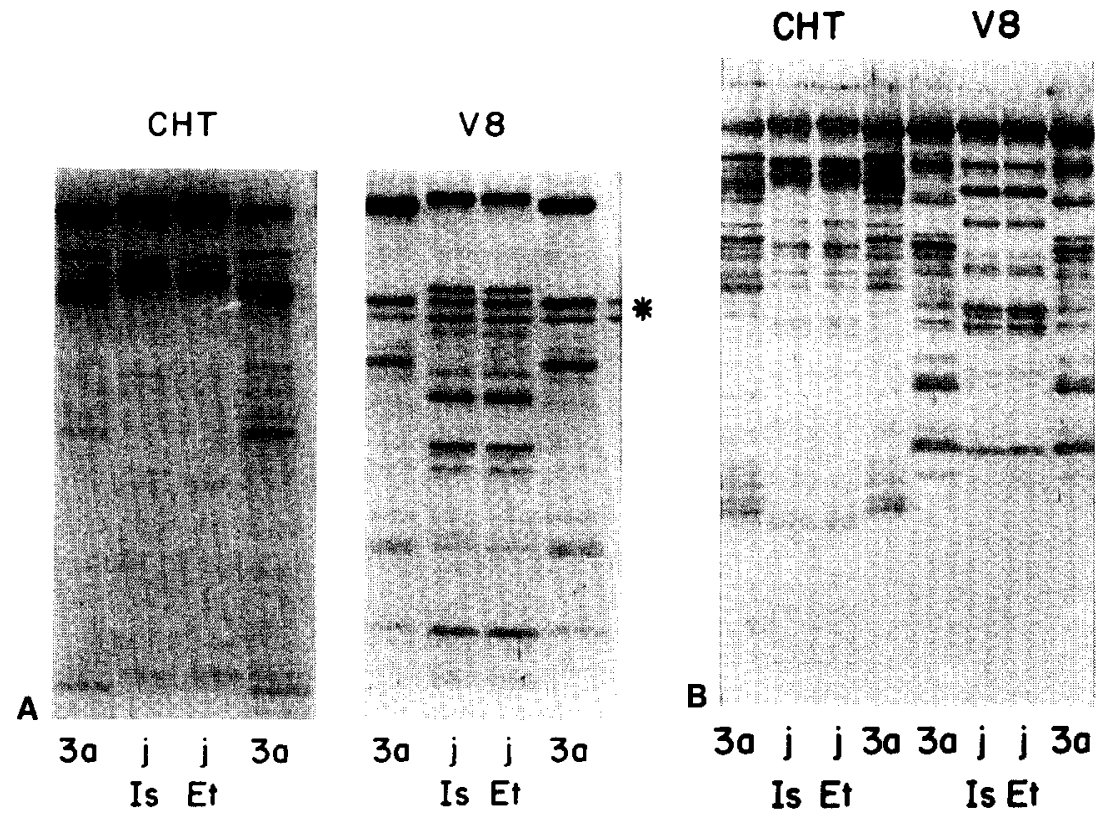

FIG. 4. Proteolytic digests of purified cytochrome $P-450 \mathrm{j}$ and isozyme $3 \mathrm{a}$ detected by protein (A) and immunochemical (B) staining. In part $A$, rabbit cytochrome $P-450$ isozyme $3 a(3 a)$ and cytochrome $P-450$ j preparations (j) from isoniazid (IS)- or ethanol (ET)-treated rats were treated with SDS and subjected to limited proteolytic digestion. In the experiment on the left, isozyme 3a was incubated with either $0.05 \mathrm{mg}$ (first well) or $0.10 \mathrm{mg}$ (last well) of chymotrypsin (CHT) per mg of protein in the sample analyzed, and the rat hemoproteins were treated with the higher amount of CHT. The gel on the right shows the peptide digests of isozyme $3 \mathrm{a}$ after incubation with $0.30 \mathrm{mg}$ (first well) or $0.45 \mathrm{mg}$ (last well) Staphylococcus aureus V8 protease (V8)/mg protein. The rat isozymes were digested with the higher amount of V8. The asterisk denotes the mobility of V8 protease itself (two bands), which contributes to the protein-stained, but not immunochemically stained, electrophoretic patterns. The purified proteins were incubated with each protease for $10 \mathrm{~min}$ at $37^{\circ} \mathrm{C}$, and $2.5 \mu \mathrm{g}$ of each digest was applied to the gel containing $12.5 \%$ acrylamide that was $1.5 \mathrm{~mm}$ thick. Electrophoresis was performed, and proteins were stained with Coomassie blue R-250. In part B, each isozyme was treated wih CHT or V8 as described in part A. Each proteolytic digest (1 $\mu \mathrm{g}$ of protein) was submitted to electrophoresis in an SDS-polyacrylamide gel containing $12.5 \%$ acrylamide that was $0.75 \mathrm{~mm}$ thick. The peptides were electrophoretically transfered to nitrocellulose and immunochemically stained with anti-3a serum as previously detailed (51).

rations of cytochrome $P-450$ j are identical by immunochemical detection. Antibody to isozyme 3a apparently recognized all of the peptides that were made visible by protein staining as well as additional minor peptides that were not detected in the experiment shown in Fig. 4A. Therefore, despite the apparent differences in proteolytic digests of the rat and rabbit isozymes, significant structural homology exists between these proteins.

Several experiments were performed to determine the effects of antibody to cytochrome $\boldsymbol{P} \mathbf{- 4 5 0}$ isozyme 3 a on catalysis sup- ported by purified cytochrome $P-450 \mathrm{j}$ and rat liver microsomal preparations, with the results shown in Figs. 5-7. The $p$-hydroxylation of aniline catalyzed by the reconstituted system containing cytochrome $P-450$ j or isozyme $3 \mathrm{a}, \mathrm{NADPH}-\mathrm{cyt}$ tochrome $P-450$ reductase from rabbit liver, and optimal phospholipid, is subject to marked inhibition by antibody to isozyme $3 \mathrm{a}$ (Fig. 5). At several antibody-to-cytochrome $P$ 450 ratios, the inhibition of metabolism by isoniazid-inducible cytochrome $P-450$ j paralleled the inhibition of that by ethanolinducible cytochrome $P-450 \mathrm{j}$, indicating 


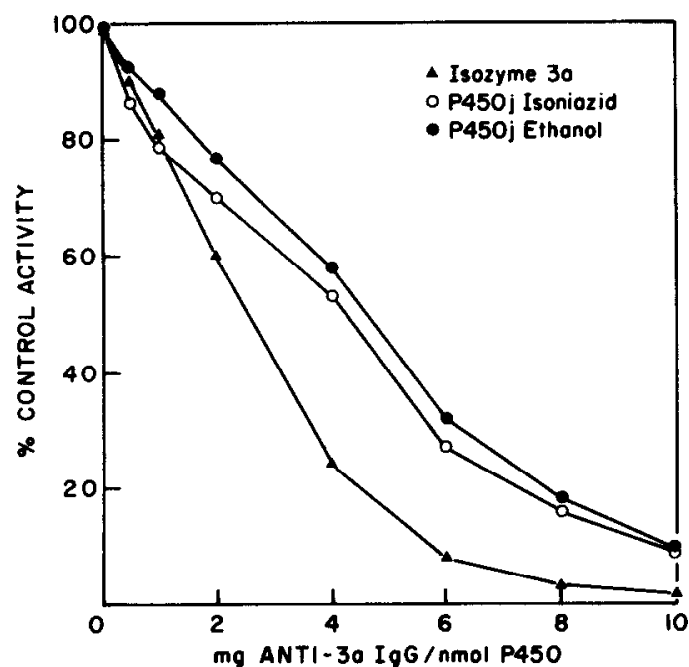

FIG. 5. Effect of anti-3a IgG on aniline hydroxylation catalyzed by purified cytochromes $P-450$ j and isozyme $3 \mathrm{a}$. The reaction mixtures $(1.0 \mathrm{ml})$ contained $0.1 \mathrm{nmol}$ cytochrome $P-450,0.3 \mathrm{nmol}$ NADPH-cytochrome $P$ 450-reductase purified from rabbit liver, 15-30 $\mu \mathrm{g}$ phosphatidylcholine, $1 \mathrm{mg}$ total antibody, $2.5 \mathrm{~mm}$ aniline, and $0.1 \mathrm{M}$ potassium phosphate buffer ( $\mathrm{pH} 7.4$ ). Anti-3a IgG and preimmune sheep IgG were added in various ratios to maintain a total of $1 \mathrm{mg}$ of protein. The samples were preincubated for $3 \mathrm{~min}$ at $37^{\circ} \mathrm{C}$, and the reactions were started with the addition of NADPH (1 mM). Metabolism proceeded for $10 \mathrm{~min}$ at $37^{\circ} \mathrm{C}$, and the reactions were terminated by the addition of TCA. Additional details for the assay protocol have been reported elsewhere $(16,41)$.

that the two preparations are equally sensitive to the antibody. Greater than $90 \%$ inhibition of aniline metabolism by the rat liver isozymes was achieved at an antibodyto-cytochrome $P-450$ ratio of $10 \mathrm{mg} / \mathrm{nmol}$. As illustrated in Fig. 5, isozyme $3 \mathrm{a}$ is more sensitive than cytochrome $P-450 \mathrm{j}$ to antibody inhibition, as would be expected. For example, at $4 \mathrm{mg}$ antibody/nmol cytochrome $P-450$, approximately $55-60 \%$ of the cytochrome $P-450 \mathrm{j}$-supported activity is retained, whereas only $25 \%$ of the isozyme 3a-catalyzed metabolism remains.

As evidenced from the data shown in Fig. 6 , rat liver microsomal aniline $p$-hydroxylation is subject to inhibition by antibody to rabbit isozyme 3a. Since this antibody specifically recognizes cytochrome $P-450$ j in the microsomal preparations from induced rats, based on results of immuno- blots (Fig. 3), the observed inhibition is probably a reflection of the cytochrome $P$ $450 \mathrm{j}$ component of the microsomes. The microsomal preparation from untreated rats catalyzed the $p$-hydroxylation of aniline with a rate of approximately $1.0 \mathrm{nmol}$ $p$-aminophenol $/ \mathrm{min} / \mathrm{nmol}$ cytochrome $P$ 450 , which was inhibited greater than $70 \%$ by $7.5-10.0 \mathrm{mg}$ antibody/nmol cytochrome $P-450$. The residual catalytic activity may be attributable to other cytochromes $P-450$ that participate in aniline metabolism but are not recognized by the antibody. Several laboratories have reported a marked increase in aniline $p$-hydroxylation in microsomes following treatment of rats with isoniazid or ethanol $(6,9,10,15)$. In the experiment illustrated in Fig. 6, turnover numbers of 4.7 and $3.9 \mathrm{nmol} p$-aminophenol $/ \mathrm{min} / \mathrm{nmol}$ cytochrome $P-450$ were determined for the microsomal samples from isoniazid- and ethanol-treated rats, respectively. Greater than $90 \%$ of this metabolism was inhibited by antibody to isozyme $3 \mathrm{a}$, thus indicating that aniline $p$-hy-

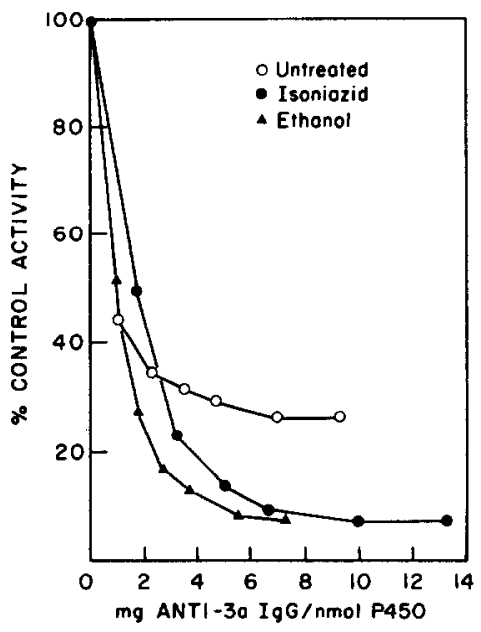

FIG. 6. Effect of anti-3a IgG on rat hepatic microsomal aniline hydroxylation. The reaction mixtures $(1.0 \mathrm{ml})$ contained $0.2 \mathrm{mg}$ microsomal protein from untreated, isoniazid-, or ethanol-treated rats, $0.1 \mathrm{M}$ potassium phosphate buffer ( $\mathrm{pH} 7.4$ ), $2.5 \mathrm{mM}$ aniline, and a sum of $2.0 \mathrm{mg}$ of IgG protein with different ratios of anti-3a IgG and preimmune sheep IgG. The mixtures were preincubated for $3 \mathrm{~min}$ at $37^{\circ} \mathrm{C}$, NADPH ( $1 \mathrm{mM}$ ) was added, and the samples were incubated for $10 \mathrm{~min}$ at $37^{\circ} \mathrm{C}$. 


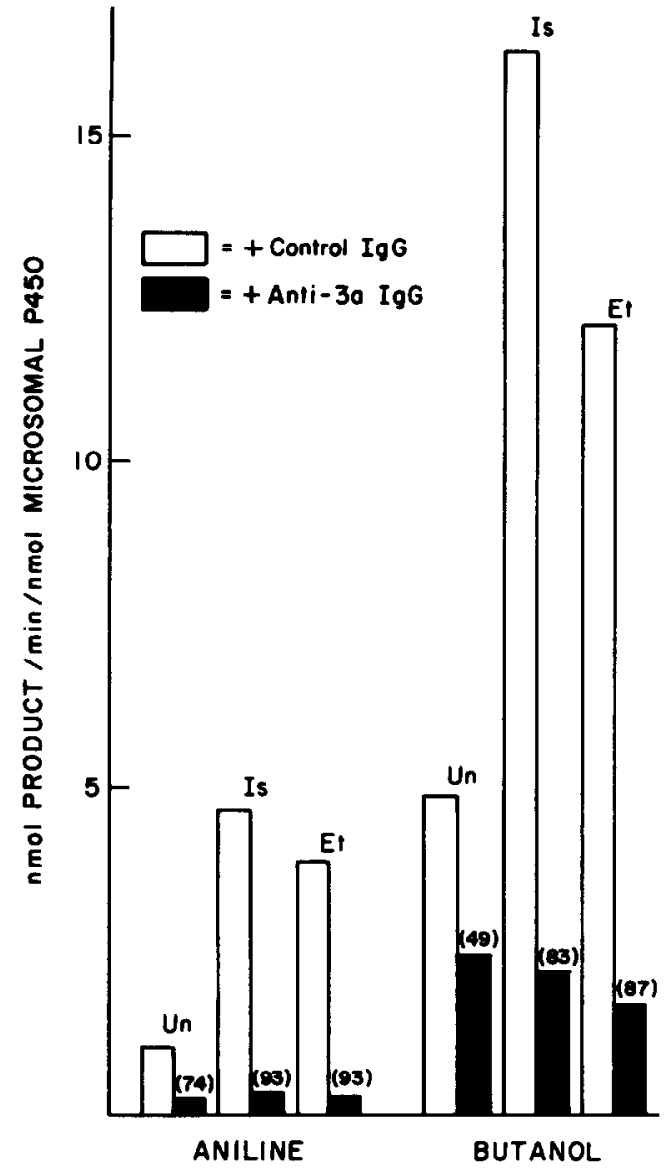

FIG. 7. Effect of anti-3a IgG on rat hepatic microsomal butanol oxidation. Microsomes were prepared from untreated ( $\mathrm{Un}$ ) rats and animals treated with either isoniazid (Is) or ethanol (Et). Butanol oxidation was measured as previously reported $(18,44)$. The assay components were $0.2 \mathrm{mg}$ microsomal protein, 0.1 M potassium phosphate buffer ( $\mathrm{pH} 7.4$ ), $30 \mathrm{~mm}$ butanol, and $2.0 \mathrm{mg}$ of either control IgG or anti-3a IgG. The samples were preincubated for $3 \mathrm{~min}$ and incubated for $10 \mathrm{~min}$ at $37^{\circ} \mathrm{C}$. The data on aniline hydroxylation were derived from the experiment shown in Fig. 6 . The values listed in parentheses are the percentage inhibition of metabolism.

droxylation catalyzed by these microsomal preparations is primarily cytochrome $P$ $450 \mathrm{j}$-mediated.

Antibody to rabbit cytochrome $P-450$ isozyme 3a is also capable of markedly inhibiting butanol oxidation in rat liver microsomes, as evidenced by the data illustrated in Fig. 7. In the presence of control
IgG, turnover numbers of $4.8,16.3$, and 12.1 were calculated for microsomes from untreated, isoniazid-treated, and ethanoltreated rats, respectively. Approximately $49 \%$ of this catalytic activity in microsomes from untreated rats was inhibited by the antibody at a ratio of $10 \mathrm{mg} \mathrm{IgG} / \mathrm{mg} \mathrm{mi-}$ crosomal protein, whereas $87 \%$ of butanol oxidation catalyzed by microsomes from the induced rats was inhibited at the same ratio of antibody to microsomal protein. These results indicate that cytochrome $P$ $450 \mathrm{j}$ is the primary catalyst of butanol oxidation in microsomes from rats induced with ethanol or isoniazid, but other cytochromes $P-450$ participate in this metabolic pathway in microsomes from untreated rats. The potency of the antibody to isozyme $3 \mathrm{a}$ as an inhibitor of two metabolic activities associated with cytochrome $P-450$ j (butanol oxidation and aniline $p$-hydroxylation) in microsomes from rats treated with either ethanol or isoniazid is similar ( 87 and $93 \%$ inhibition). As shown in Fig. 7, however, greater inhibition of aniline metabolism than butanol oxidation was attained in microsomes from untreated rats. Yang et al. (55) have reported that antibody to isozyme 3a inhibited $>90 \%$ of NDMA demethylation catalyzed by liver microsomes from ethanoltreated rats.

The effectiveness of ethanol and isoniazid as inducers of rat liver microsomal cytochrome $P-450$ j can be estimated on the basis of antibody-inhibited rates of aniline and butanol metabolism as listed in Table II. If the increase in these microsomal catalytic activities is due entirely to higher levels of cytochrome $P-450 \mathrm{j}$ induced by isoniazid or ethanol treatment, then the data presented in Table II indicate that isoniazid is a slightly better inducer of cytochrome $P-450$ j than ethanol. Cytochrome $P-450$ j-dependent aniline and butanol metabolism increases 580 and $597 \%$, respectively, by isoniazid treatment and 480 and $445 \%$, respectively, by ethanol treatment of adult male rats. Although this approach may underestimate the induction of cytochrome $P-450 \mathrm{j}$ by these compounds as suggested by observations of Koop et al. (21) with isozyme $3 a$, our limited data from im- 
TABLE II

Induction of Rat Hepatic Cytochrome $P$-450j as Determined by ANTi-3a IgG InHibition

\begin{tabular}{ccccc}
\hline & \multicolumn{4}{c}{$\begin{array}{c}\text { Antibody-inhibited rate } \\
\text { (nmol product/min/nmol cytochrome } P-450)\end{array}$} \\
\cline { 2 - 5 } Rat treatment & $\begin{array}{c}\text { Aniline } \\
\text { hydroxylation }\end{array}$ & $\begin{array}{c}\% \text { of } \\
\text { control }\end{array}$ & $\begin{array}{c}\text { Butanol } \\
\text { oxidation }\end{array}$ & $\begin{array}{c}\% \text { of } \\
\text { control }\end{array}$ \\
\hline Control & 0.75 & 100 & 2.36 & 100 \\
Isoniazid & 4.35 & 580 & 14.1 & 597 \\
Ethanol & 3.59 & 480 & 10.5 & 445 \\
\hline
\end{tabular}

Note. Hepatic microsomes were prepared from adult male rats treated with isoniazid or ethanol as described. The assays for aniline and butanol metabolism have been reported. The rates of anti-3a IgG-inhibited metabolism were calculated by sublracling the rates ublained in the presence of maximum levels of anti-3a IgG from the rates obtained in the presence of the same concentrations of preimmune sheep IgG.

munoblots are consistent with results presented in Table II.

In summary, the results of this study indicate that the same isozyme, cytochrome $P-450$ j, is induced by ethanol as well as isoniazid treatment of rats. Cytochrome $P$ $450 \mathrm{j}$ purified from ethanol-treated rats has chromatographic, electrophoretic, immunochemical, spectral, catalytic, and structural properties identical to those of the corresponding isozyme from isoniazidtreated rats. The ethanol-inducible enzyme appears to be closely related to rabbit liver isozyme $3 \mathrm{a}$ on the basis of several criteria. Significant structural homology has also been demonstrated for phenobarbital- and 3-methylcholanthrene-inducible rat and rabbit liver cytochrome $\boldsymbol{P}$-450 isozymes (58, 59 ). We conclude from this study that cytochrome $P-450 \mathrm{j}$ is the rat homolog of rabbit liver cytochrome $P-450$ isozyme $3 a$.

\section{ACKNOWLEDGMENT}

We thank Ms. Cathy Michaud for her assistance in the preparation of this manuscript.

\section{REFERENCES}

1. Conney, A. H. (1967) Pharmacol Rev. 19, 317-366.

2. Lu, A. Y. H., AND Levin, W. (1974) Biochim. Biophys. Acta 344, 205-240.

3. Coon, M. J. (1981) Drug Metab. Dispos. 9, 1-4.

4. Miller, E. C., AND Miller, J. A. (1981) Cancer (Philadelphia) 47, 2327-2345.
5. Comai, K., ANd GaYlor, J. L. (1973) J. Biol. Chem. 248, 4947-4955.

6. Villeneuve, J. P., Mavier, P., and Joly, J. G. (1976) Biochem. Biophys. Res. Commun. 70, 723728.

7. OHNISHI, K., AND Lieber, C. S. (1977) J. Biol Chem. 252, 7124-7131.

8. Sharma, R. N., Cameron, R. G., Fakber, E., Griffin, M. J., Joly, J. G., AND Murray, R. K. (1979) Biochem. J. 182, 317-327.

9. RICE, S. A., AND TaLCOTT, R. E. (1979) Drug Metab. Dispos. 7, 260-262.

10. Morgan, E. T., Devine, M., And Skett, P. (1981) Biochem. Pharmacol. 30, 595-600.

11. Peng, R., TU, Y. Y., AND YANG, C. S. (1982) Carcinogenesis (London) 3, 1457-1461.

12. Rice, S. A., Dooley, J. R., AND MAzZe, R. I. (1983) Anesthesiology 58, 237-241.

13. Gadeholt, G. (1984) Biochem. Pharmacol 33, 3047-3051.

14. Ryan, D. E., IIda, S., Wood, A. W., Thomas, P. E., Lieber, C. S., AND Levin, W. (1984) $J$. Biol. Chem. 259, 1239-1250.

15. Ryan, D. E., Ramanathan, L., Iida, S., Thomas, P. E., Haniu, M., Shively, J. E., Lieber, C. S., AND Levin, W. (1985) J. Biol. Chem. 260, 63856393.

16. KoOP, D. R., Morgan, E. T., TARR, G. E., AND CoON, M. J. (1982) J. Biol. Chem. 257, 8472-8480.

17. KoOP, D. R., AND COON, M. J. (1984) Mol Pharmacol 25, 494-501.

18. Morgan, E. T., Koop, D. R., AND CoON, M. J. (1982) J. Biol Chem. 257, 13951-13957.

19. CoON, M. J., Koop, D. R., AND MORGAN, E. T. (1983) Pharmacol Biochem. Behav. 18, 177-180.

20. Yang, C. S., Tu, Y. Y., KooP, D. R., AND CoON, M. J. (1985) Cancer Res. 45, 1140-1145.

21. Koop, D. R., CRuMP, B. L., Nordblom, G. D., AND 
Coon, M. J. (1985) Proc. Natl. Acad. Sci. USA 82, 4065-4069.

22. INGELMAN-SUNDBERG, M., AND JORNVALL, H. (1984) Biochem. Biophys. Res. Commun 124, 375-382.

23. Ryan, D. E., Thomas, P. E., ReIK, L. M., AND LEvin, W. (1982) Xenobiotica 11, 727-744.

24. Lieber, C. S., AND De CarLI, L. M. (1970) Amer. J. Clin. Nutr. 23, 474-478.

25. Dignam, J. D., AND STRobel, H. W. (1975) Biochem. Biophys. Res. Commun. 63, 845-852.

26. Yasukochi, Y., AND MASTers, B. S. S. (1976) J. Biol. Chem. 251, 5337-5344.

27. PhIllips, A. H., AND Langdon, R. G. (1962) J. Biol Chem. 237, 2652-2660.

28. French, J. S., AND Coon, M. J. (1979) Arch. Biochem. Biophys. 195, 566-577.

29. KoOP, D. R., Nordblom, G. D., ANd Coon, M. J. (1984) Arch. Biochem. Biophys. 235, 228-238.

30. Thomas, P. E., ReIK, L. M., RYan, D. E., AND LeVIN, W. (1981) J. Biol Chem. 256, 1044-1052.

31. Thomas, P. E., Lu, A. Y. H., Ryan, D., West, S. B., KAWALEK, J., AND LEVIN, W. (1976) J. Biol. Chem. 251, 1385-1391.

32. KuPfer, D., AND Rosenfeld, J. (1973) Drug Metab. Dispos. 1, 760-765.

33. Kapitulnik, J., Poppers, D. J., and Conney, A. H. (1977) Clin. Pharmacol Ther. (St. Lonis) 21, 166-176.

34. Nebert, D. W., ANd Gelboin, H. V. (1968) J. Biol. Chem. 243, 6242-6249.

35. Tomaszewski, J. E., JERINA, D. M., LEvin, W., AND Conney, A. H. (1976) Arch. Biochem. Biophys. 176, 788-798.

36. Numazawa, M., KiYono, Y., and Nambara, T. (1980) Anal. Biochem. 104, 290-295.

37. Greenlee, W. F., And Poland, A. (1978) J. Pharmacol. Exp. Ther. 205, 596-605.

38. NetTer, K. J., AND SEIDEL, G. (1964) J. Pharmacol. Exp. Ther. 146, 61-66.

39. Gustafsson, J.-A., AND InGelman-SundBerG, M., (1974) J. Biol. Chem. 249, 1940-1945.

40. Ryan, D. E., Dixon, R., Evans, R. H., RamanaTHAN, L., THOMAS, P. E., WoOD, A. W., AND LEvin, W. (1984) Arch. Biochem. Biophys. 233, 636-642.

41. Mieyal, J. J., ACKerman, R. S., Blumer, J. L., AND
Freeman, L. S. (1976) J. Biol. Chem. 251, 34363441.

42. Hutton, J. J., MeieR, J., AND HACKNEY, C. (1979) Mutat. Res. 66, 75-94.

43. HaWke, R. L., AND WELCH, R. M. (1985) Mol. Pharmacol. 27, 283-289.

44. Lieber, C. S., AND De CARLI, L. M. (1968) Science $162,917-918$.

45. VAN DER Hoeven, T. (1981) Biochem. Biophys. Res. Commun. 100, 1285-1291.

46. Wood, A. W., Ryan, D. E., Thomas, P. E., AND LEVIN, W. (1983) J. Biol. Chem. 258, 8839-8847.

47. LAEMMLI, U. K. (1970) Nature (London) 227, 680685.

48. WraY, W., BoUlikas, T., WRaY, V. P., AND HaNcock, R. (1981) Anal Biochem. 118, 197-203.

49. Clevveland, D. W., Fischer, S. G., Kirschner, M. W., AND LaEmmLi, U. K. (1971) J. Biol. Chem. 252, 1102-1106.

50. Ryan, D. E., Thomas, P. E., ANd Levin, W. (1980) J. Biol. Chem. 255, 7941-7955.

51. Thomas, P. E., ReIK, L. M., RYAN, D. E., AND LEviN, W. (1984) J. Biol Chem. 259, 3890-3899.

52. Lowry, O. H., Rosebrough, N. J., FARR, A. L., AND Randall, R. J. (1951) J. Biol. Chem. 193, 265-275.

53. OMura, T., AND Sato, R. (1964) J. Biol Chem. 239, 2379-2385.

54. Sladek, N. E., ANd Mannering, G. J. (1966) Biochem. Biophys. Res. Commun. 24, 668-674.

55. YANG, C. S., KOOP, D. R., WANG, T., AND COON, M. J. (1985) Biochem. Biophys. Res. Commun. 128, 1007-1013.

56. Thomas, P. E., ReIK, L. M., RYaN, D. E., AND LEVIN, W. (1983) J. Biol. Chem. 258, 4590-4598.

57. Ryan, D. E., Wood, A. W., Thomas, P. E., Walz, F. G., JR., Yuan, P. M., ShIvely, J. E., AND Levin, W. (1982) Biochim. Biophys. Acta 709, 273-283.

58. BlACK, S. D., AND Coon, M. J. (in press) in Cytochrome P450: Structure Mechanism and Biochemistry (Ortiz de Montellano, P., ed.), Plenum, New York.

59. Thomas, P. E., ReIDy, J., ReIK, L. M., Ryan, D. E., KooP, D. R., AND Levin, W. (1984) Arch. Biochem. Biophys. 235, 239-253. 